\title{
Irrigation in Support of Research Project: Seismic Absorption and Modulus Measurement
}

\section{$\underline{\text { Introduction }}$}

The irrigation site located at the University of Arizona Maricopa Agricultural Center was designed to support controlled irrigation through the use of evenly spaced drip tubing under a heavy black plastic tarp. Soil solution samplers (lysimeters) are placed at specific locations to collect water from 1.5 meters, 3.0 meters and 10 meters from the soil surface.

Suction provided by a vacuum pump was applied to the lysimeters for three hours prior to collection. After this time, the soil solution, if any was collected and placed into $20 \mathrm{ml}$ HDPE scintillation vials and stored at $-15^{\circ} \mathrm{C}$ for later analysis.

These samples were analyzed for $\mathrm{pH}$ with a Ross Sure Flow Combination Electrode. Electrical conductivity for each sample was measured with the use of an Accumet Conductivity Cell. Both electrodes were connected to an Accumet Model $50 \mathrm{pH} /$ ion/conductivity meter.

High Performance Liquid Chromatography was employed in an attempt to determine the amount of Biosurfactant present in each sample. Our HPLC equipment includes a $5 \mathrm{~mm}$ X $15 \mathrm{~mm} \mathrm{C18}$ chromatography column, Waters 2487 detector, 510 pump, and WISP 710 Auto Injector. Millennium software was used to integrate data from these analyses.

\section{Site preparation and maintenance}

The system needed repairs and renovation to provide the uniform and accurate distribution of water and surfactant to the study field. The surfactant was mixed in two storage tanks that needed new circulating pumps. These were automated to run before and during each application. New control valves were added as the old valves were leaking when the system was not operating. A second flow meter was added to verify applied rates and volumes. The air bleed offs were replaced at each end of the drip system to help balance the pressures and flows into the system more quickly. The drip tubing was repaired and portions replaced as needed to insure even and leak free applications. The HDPE cover needed repairs and sealing to prevent unwanted precipitation from entering the study site. As precipitation fell it was collected and a new pump installed to carry the water away from the site. Time clocks were programmed to operate pumps and valves to specified parameters. The wiring for the valves, pumps and time controllers was inspected and replaced as needed.

\section{$\underline{\text { Results }}$}

The field was irrigated for two weeks prior to sampling. Samples were collected at 20 dates from November 2, 2004 to February 5, 2005. A total of 316 samples were collected during this period. Not all of the suction lysimeters provided a soil solution sample. In some cases, only a small amount, about 5 milliliters were collected.

A total of 600 analyses were conducted on these 316 samples for $\mathrm{pH}$ and EC. All 316 samples were analyzed for EC. Only 284 samples were analyzed for $\mathrm{pH}$, due to the small volume of solution collected. A minimum of 10 milliliters is required for $\mathrm{pH}$ analysis. There were differences in $\mathrm{pH}$ and $\mathrm{EC}$ of the various soil solutions at different depths and sample dates, but this is quite common for soil solutions. 
Samples of irrigation water with and without the biosurfactant were collected for comparison. There was no difference in $\mathrm{pH}$ or $\mathrm{EC}$ between untreated and treated irrigation water.

The biosurfactant was not detected in any soil solution sample. Numerous combinations of water, acetonitrile, methanol and chloroform were tested as the mobile phase in the HPLC procedure. There was no positive response in any results (peak-heights and areas) for any samples.

The results of the samples corresponded to the results obtained by Dr. Hartmut Spetzler. Evidently, there was no measurable surface tension difference between any of the samples he had tested with equipment at his facility in Colorado. It is apparent that the detection equipment doesn't have the required sensitivity to measure surface tension differences for these samples. All data collected from the Maricopa Agricultural Center were forwarded to Dr. Hartmut Spetzler for the final analysis of the study. 